\title{
Cartografias imaginadas: Brasil e Cabo Verde na rota dos signos
}

\author{
Immaginary cartographies: brazil and cape verde in the route of signs
}

\section{Ana Claudia Aymoré Martins ${ }^{1}$}

\begin{abstract}
Palestra proferida em 2 de setembro de 2008 na Universidade de Cabo Verde (UNICV), na cidade de Praia, a convite do Centro de Estudos Brasileiros (CEB), como parte das atividades da Semana da Pátria. Texto revisto e ligeiramente modificado em junho de 2015.
\end{abstract}

Ilha de Santiago/Tem corpinho de algodón/Saia de chita cu cordón/Um par de brinco roda pión: assim canta o compositor cabo-verdiano Mario Lucio sua terra de origem (LUCIO, 2005). Inicia seu canto com a palavra "ilha", apontando desde então para o marco zero de uma cartografia imaginária, toda ela representada pelo movimento e pela circularidade (corpinho de algodão, saia de chita, brincos, roda, pião). Santiago emerge, portanto, como espaço imaginado a partir dessa dupla referência: como entrelugar de fronteiras móveis, por um lado; simultaneamente, como o espaço que estabelece uma ruptura física com tudo o que não seja ele próprio, encerrado em si como um círculo. Essa imagem simultaneamente cambiante e autocentrada que encontramos aqui, não por acaso, está no cerne de diversas utopias insulares, sendo que, na modernidade, à medida que se constitui e se torna hegemônico o conceito de Nação e o sentimento nacionalista que o fortalece e justifica, a Terra-natal é frequentemente semantizada - literal ou metaforicamente - como ilha. Brasil e Cabo Verde, nações que, como nos mostra o historiador Daniel Pereira, compartilham diversos momentos de seu passado histórico (PEREIRA, 1986 e 2011), também dividem essa recorrência da temática da insularidade utópica ao longo do processo de construção de suas respectivas identidades nacionais - sob essa ótica, nosso objetivo aqui seria o de reconhecer, sob as formas que o motivo da ilha assume nas culturas brasileira e caboverdiana, as reverberações dos mitos fundacionais.

Mas quais as relações entre a ilha como signo, a construção da identidade e a formação de utopias? Se consultamos o Dicionário de Símbolos, nos deparamos com a seguinte definição para o verbete "ilha": "A ilha, a que se chega apenas depois de uma navegação ou de um vôo, é o símbolo por

\footnotetext{
1 Professora associada do Curso de História e do Programa de Pós-graduação em Letras e Linguística da Ufal. e-mail: ana_aymore@hotmail.com
} 
excelência de um centro espiritual e, mais precisamente, do centro espiritual primordial" (GHEERBRANT e CHEVALIER, 1988, p. 501). Lugar de refúgio e isolamento, a ilha simboliza a origem e o centro, o espaço ancestral do qual o homem é afastado para ser lançado no caos do mundo civilizado. Como o ideal de retorno ao vente materno, retornar à prazerosa e protegida vida insular representa a volta a um tempo anterior à cultura, e por isso mesmo alheio aos pecados e privações da vida em sociedade.

Além disso, a ilha pode ser vista como um microcosmo, um mundo em miniatura, com a vantagem de, por seu isolamento, ser um espaço inacessível para a maioria; portanto, um refúgio para os eleitos. Ocidente e Oriente são igualmente ricos em lendas acerca de deuses ou personagens redentores refugiados numa ilha, esperando o momento propício para o retorno à história - o rei Arthur, em Avalon; D. Sebastião, na ilha do Encoberto; Quetzalcoátl, em Aztlan. Ilhas dos mortos, como a ilha de Brítia descrita pelo historiador bizantino Procópio de Cesareia ou a ilha na qual, segundo Plutarco, jaz adormecido o deus Cronos; ilhas habitadas somente por mulheres, ou por seres fabulosos, ou ainda por uma humanidade mais desenvolvida; as ilhas Afortunadas visitadas por São Brandão, onde "a terra produz tudo quanto possa deleitar a vista e embriagar o olfato" (ROTTERDAM, 1979, p. 13); país da Cocanha, no qual os desejos se realizam imediatamente: em todas elas, há em comum a miragem do Paraíso Terrestre, o lugar da bem-aventurança, incontaminado pelos desvarios da civilização.

Sob essa perspectiva, a ilha deixa de ser apenas espaço geográfico concreto para se tornar, num sentido muito mais amplo, figura, ou seja, representação de um topos imaginado, como proposto por Ettore Finazzi-Agró; isto é, uma figura geográfica, evidentemente, mas também figura na acepção mais ampla de um espaço onde se projetam, se acumulam e se condensam uma série de práticas representativas ou, ainda, o lugar "que se expõe à precariedade sem fim da interpretação simbólica, ao flutuar histórico das alegorias morais, políticas, religiosas" (FINAZZI-AGRÓ, 1993, p. 94). Desse modo, a ilha tem, ao mesmo tempo, consistência "topográfica", como fragmento espacial reconhecível e mensurável, e uma imaterialidade "tópica" como lugar "ilocável em que se juntam e se sedimentam imagens muitas vezes contraditórias" (FINAZZI-AGRÓ, 1993, p. 94).

Situada entre o existente e 0 imaginado, a figura da ilha não se reduz, portanto, à mera apreensão realista de um meio geográfico. Não é por acaso que o instante primevo do encontro da América pelos europeus é, na verdade, o encontro com uma natureza mítica, a qual obedecia, ao menos em grande parte, a juízos apriorísticos do quadro mental deste momento inaugural da modernidade europeia. Talvez o exemplo mais contundente dessa questão seja o do próprio mito da "ilha Brasil", que envolve o descobrimento (real) do que serão durante três séculos os domínios 
portugueses na América. Erroneamente, ao utilizar uma interpretação literal do Capítulo Segundo da famosa História do Brasil de Frei Vicente do Salvador, datada de 1627, as cartilhas escolares insistiram por muito tempo em relacionar o nome Brasil de forma unívoca à exploração comercial - 0 primeiro produto econômico do lugar, chamado "pau-brasil". O trecho em questão é o seguinte:

O dia em que o capitão-mor Pedro Álvares Cabral levantou a cruz, que no capítulo atrás dissemos, era a 3 de maio, quando se celebra a invenção da santa cruz em que Cristo Nosso Redentor morreu por nós, e por esta causa pôs nome à terra que havia descoberta de Santa Cruz e por este nome foi conhecida muitos anos. Porém, como o demônio com o sinal da cruz perdeu todo o domínio que tinha sobre os homens, receando também perder o muito que tinha em os desta terra, trabalhou que se esquecesse o primeiro nome e lhe ficasse o de Brasil, por causa de um pau assim chamado de cor abrasada e vermelha com que tingem panos, do qual há muito, nesta terra, como que importava mais o nome de um pau com que tingem panos que o daquele divino pau, que deu tinta e virtude a todos os sacramentos da Igreja, e sobre que ela foi edificada e ficou tão firme e bem fundada como sabemos. $E$ porventura por isto, ainda que ao nome de Brasil ajuntaram o de Estado e lhe chamam Estado do Brasil, ficou ele tão pouco estável que, com não haver hoje cem anos, quando isto escrevo, que se começou a povoar, já se hão despovoados alguns lugares e, sendo a terra tão grande e fértil como ao diante veremos, nem por isso se vai em aumento, antes em diminuição. (SALVADOR, 1965)

Como podemos ver, ao nome "Terra de Santa Cruz" sobrepõe-se o de "Estado do Brasil", segundo Frei Vicente, porque os homens, instigados pelo Mal, subjugaram ao "pau que tinge panos" (o pau-brasil) aquele "divino pau" (a Santa Cruz de Cristo), o único capaz de dar "tinta e virtude" à nova terra. Ora, muito mais do que um dado concreto de que o nome do Brasil é uma decorrência da exploração do pau-brasil, a análise de frei Vicente pode bem ser lida como uma construção metafórica e antitética. Busca, sobretudo, legitimar a posição de um homem da Igreja frente à ascensão do caráter mercantil da colonização, em detrimento do caráter cruzadista da conversão das almas, ou, se fizermos uma leitura extemporânea, à percepção do jesuíta do irresistível triunfo da modernidade sobre as práticas e valores medievais. Antecedendo essa discussão, encontramos a misteriosa llha do Brazil da mitologia irlandesa, descrita e mapeada por cartógrafos medievais, com inúmeras variantes como Brazi, Brazir, Breasail, Braçir, O’Brazil a qual só foi totalmente apagada dos mapas no século XIX. Ela

Era usualmente localizada a algumas centenas de milhas a oeste do sul da Irlanda, e descrita como circular, ou como um anel de ilhotas. Essa terra assombrada manteve-se viva através de relatos como o de um certo Capitão Nisbet que em 1674 aportou na Escócia com sobreviventes de um naufrágio supostamente resgatados da llha do Brazil. Ele disse que a 
ilha era habitada por gigantescos coelhos negros e por um mago que estaria mantendo os náufragos cativos em seu castelo até o próprio capitão quebrar o feitiço que os enclausurava. (DE CAMP, s.d., p. 25)

No mapa de Andréa Bianco, de 1436, a ilha Brasil dos celtas já surge deslocada para as proximidades dos Açores, e sua lenda era, na época, mais relacionada à suposta "ilha dos bemaventurados" de São Brandão. Portanto, já há no imaginário europeu uma "ilha Brasil" que antecede em muito seu descobrimento real, fator que não deve de forma alguma ser desconsiderado na interpretação dos escritos dos primeiros viajantes, quase todos marcados por aquele traço que a historiadora Laura de Mello e Souza chamou de "edenização da natureza" (SOUZA, 1987). Embora perpassada por uma lógica utilitarista, a própria Carta de Caminha, texto de fundação de identidade nacional brasileira, não deixa de ser pontuada claramente por essa percepção de encontro do Paraíso terrestre, nos comentários sobre a riqueza da terra, a beleza e nudez dos nativos, a cordialidade nos primeiros contatos entre as duas culturas. Mesmo a sugestiva coincidência da descoberta da "ilha de Vera Cruz" durante a Semana Santa, período no qual se atualiza a promessa de redenção da cristandade, parece remeter, para 0 autor e possivelmente para o destinatário, D. Manuel, a um sinal da graça divina. A perfeição do lugar alcançado o aproxima da fictícia ilha de Thomas Morus, como assinala Thomas Sträter em artigo sobre a utopia da ilha Brasil, quando diz que "Como no caso da ilha de Caminha, a Utopia existia como representação figurativa inscrita num contexto preexistente" (STRÄTER, 2000, P. 15)

E não podemos nos esquecer, decerto, que a história do Brasil e de Cabo Verde entrelaça-se desde esse momento inaugural: de São Nicolau, em Cabo Verde, partem as naus cabralinas para efetuar a trajetória decisiva para o Descobrimento do Brasil, como expresso literalmente na Carta; ademais, a própria posse do Brasil pelos portugueses legitimou-se a partir do ponto de referência caboverdiano, no Tratado de Tordesilhas. Daí em diante, a montagem do Antigo Sistema Colonial consolidou essa rota inaugural entre os dois espaços, fazendo de Cabo Verde nexo obrigatório de ligação entre África e Brasil para o tráfico de escravos, um deslocamento contínuo de corações e mentes que atou definitivamente os laços entre os dois continentes através do "Atlântico negro" (GILROY, 2001), mas também componente decisivo na constituição do discurso e da prática eurocêntrica dominante: afinal, os "negros-Cabo Verde", os escravos ladinizados, são aqueles que, submetidos à fé e aos traços culturais do colonizador, apresentam-se como "sabendo fazer tudo, até tocar música" (Apud PEREIRA, 2011, p. 39); são os "clérigos e cônegos tão negros como azeviche" descritos com estupefação pelo padre Antonio Vieira em sua chegada na cidade de Praia em 1652, 
"tão compostos, tão autorizados, tão doutos, tão grandes músicos, tão discretos e bem morigerados, que podem fazer invejas aos que lá vemos nas nossas Catedrais" (apud SILVA, 2003).

Em Cabo Verde, assim como no Brasil, a topografia mítica está intimamente ligada, como já dissemos, ao próprio processo de autorrepresentação. Nesse caso, o fato de ambos terem sido, no passado, áreas de possessão colonial portuguesa não pode deixar de ser considerado, pois sendo a colonização portuguesa fortemente marcada, como já apontava Sérgio Buarque de Holanda, por um forte pragmatismo e pela tendência à descentralização, acabou por constituir espaços coloniais múltiplos e fragmentários (HOLANDA, 2006): no caso do Brasil, não estaríamos exagerando se disséssemos que, a despeito da existência de um Governo Geral para toda a colônia, o único fator de unidade do Brasil naqueles tempos era a língua. Às vésperas da independência, nem sentimentos nativistas nem interesses em comum faziam a ligação entre as distantes e atomizadas províncias brasileiras - o caráter regionalista e separatista dos chamados "movimentos precursores da independência do Brasil", incluindo a Inconfidência Mineira, são evidências bastante conhecidas dessa constatação. Unificado de forma autoritária pelo príncipe-herdeiro do trono português e convertido a uma monarquia anacrônica (pois muito possuía ainda de Ancien Régime), o Brasil cambiou repentinamente da fragmentação colonial para a unificação sob a égide do cetro e da coroa imperiais. Isso não impediu, no entanto, que as tensões entre o local e o nacional continuassem existindo, levando até, em casos mais extremos, a persistência de desejos separatistas em várias regiões. Assim, todo o processo de formação de uma identidade nacional é colocado em xeque pela própria origem histórica, devendo ser legitimado pela via da construção - flagrantemente utópica - de uma origem mítica, da formação de nexos identitários através do discurso, notadamente o historiográfico e 0 literário. É por isso que, nos anos que sucedem a independência do Brasil, da constituição da ordem imperial, o Romantismo brasileiro - de Alencar a Gonçalves Dias -, bem como a historiografia do IHGB, tiveram como principal tarefa justamente essa formação do Brasil como "comunidade imaginada" (ANDERSON, 1989), inexistente em 1822. Também em Cabo Verde as lutas nativistas passaram necessariamente por essa mesma necessidade de transformar multiplicidade em unidade, o que encontramos, por exemplo, na criação do mito da mestiçagem em Cabo Verde, com todas suas referências, apropriações e releituras de Gilberto Freyre, na exalação do dialeto crioulo como elemento essencial de identidade nacional no famoso estudo de Baltasar Lopes da Silva (SILVA, 1984), ou na produção literária da Claridade. Se, como apontava Renan em fins do século XIX, "0 esquecimento (...) [também é] um fator essencial na criação de uma nação" (RENAN, 1997, p. 19), era preciso obliterar toda uma realidade "indesejável" de multiplicidade, de estranhezas mútuas, de conflitos e de afastamentos numa imagem única, totalizante. 
Pois de forma análoga aos mitos fundacionais que ajudaram a moldar a nacionalidade brasileira, as representações cartográficas e narrativas inaugurais de Cabo Verde pressupunham igualmente uma origem mítica para o arquipélago atlântico, no mais das vezes relacionando-o: a) de modo mais geral, com todo o conjunto das ilhas atlânticas, os Açores, as Selvagens, Madeira, as Canárias e Cabo Verde, à categoria mítica, paradisíaca e miraculosa da Macaronésia, ou das Ilhas Afortunadas, frequentemente referidas, como vimos, como espaço de repouso dos deuses ou heróis míticos; e b) particularmente ao mito clássico das Hespérides - as divindades filhas da Noite que guardavam seu jardim no extremo ocidental do mundo, além das Colunas de Hércules -, registrado na Teogonia de Hesíodo. Com demasiada recorrência, a cartografia quinhentista, de Ortelius a Oviedo, associa as ilhas de Cabo Verde à cartografia mítica do Jardim das Hespérides, relação que encontrou sua forma mais acabada, naqueles tempos, nos versos do Canto V dos Lusíadas:

\author{
Passamos o limite aonde chega \\ O Sol que pera o Norte os carros guia; \\ Onde jazem os povos a quem nega \\ O filho de Climene a cor do dia. \\ Aqui gentes estranhas lava e rega \\ Do negro Sanagá a corrente fria, \\ Onde o Cabo Arsinário o nome perde, \\ Chamando-se dos nossos Cabo Verde. \\ Passadas tendo já as Canárias ilhas, \\ Que tiveram por nome Fortunadas, \\ Entramos, navegando, polas filhas \\ Do velho Hespério, Hespéridas chamadas; \\ Terras por onde novas maravilhas \\ Andaram vendo já as nossas armadas. \\ Ali tomamos porto com bom vento, \\ Por tomarmos da terra mantimento. (CAMÕES, 1999)
}

e que ainda encontra-se presente em vários exemplos da lírica caboverdiana, dos pré-claridosos aos autores contemporâneos, sobretudo, ou pelo menos mais diretamente, na obra dos poetas José Lopes e Pedro Cardoso.

Poderíamos perguntar se essa tensão entre realidade e irrealidade fortemente presente nos mitos fundacionais cabo-verdianos não teria relações com três aspectos importantes de sua formação histórica, os quais constituir-se-iam "lapsos" na construção dos discursos identitários nacionais: 
O primeiro deles seria o da falta do elemento nativo, signo histórico comumente associado, nos discursos nacionalistas, à pureza e à origem, e que, no Brasil, fez do indianismo uma das principais características da síntese romântica de identidade nacional. Como se sabe, as ilhas do Cabo Verde eram desabitadas quando chegaram os primeiros descobridores e, portanto, só podem se constituir histórica e socialmente pela via da exterioridade: desse modo, na impossibilidade de construção de uma origem histórica pura, os elementos míticos e fantásticos assumem quase que necessariamente 0 lugar dos elementos históricos. Além disso, essa via da exterioridade encontra-se, ainda, em outros marcos identitários importantes do país, entre os quais seu próprio nome (as ilhas do Cabo Verde, nome que, na verdade, refere-se ao cabo que marca o extremo oeste do continente africano, no Senegal) e, mais contemporaneamente, ao seu caráter de cultura de diáspora, resultante do intenso processo de emigrações da ilha no último século - retratado em obras ficcionais como Os flagelados do Vento Leste, de Manuel Lopes, e Hora de bai, de Manuel Ferreira -, o que leva à necessidade constante de reconstrução e manutenção de uma identidade hoje pulverizada ao redor do mundo.

0 segundo aspecto está também ligado com as relações entre 0 arquipélago e 0 que 0 circunda: relaciona-se, sobretudo, à sedimentação histórica de Cabo Verde como espaço de passagem, pela origem histórica de suas principais cidades como entrepostos comerciais. Nem propriamente África nem América, meio-caminho entre dois continentes, a busca pela identidade em Cabo Verde debate-se nesse dilema. Curiosamente, um aspecto histórico pouquíssimo sabido no Brasil é o do movimento, no arquipélago, que sucedeu imediatamente a independência da colônia portuguesa na América, e que buscava justamente a associação entre as duas colônias (PEREIRA, 2011, pp. 57-59). Ou seja: um dia Cabo Verde pensou-se Brasil, e esse dado é, sem dúvida, muito significativo para apenas figurar como uma curiosidade histórica. Aqui, as ilhas abandonam sua fixidez geográfica e travestem-se em naus, batizadas em nomes santificados, e varridas no mar por sotavento e barlavento, emblemas de sua dinâmica condição náutica.

Finalmente, como nos mostra Manuel Ferreira, o apego à imagem mítica hesperitana seria "debitário da preocupação de construir um universo defensivo: contra a alienação patriótica e contra 0 estado extremamente carencial do arquipélago de Cabo Verde" (FERREIRA, 1985, pp. 245-246), ou seja, como forma de evasão ou mecanismo de compensação de um estado endêmico de escassez de recursos naturais causados pela seca. De fato, uma das mais marcantes características físicas do arquipélago, com múltiplos desdobramentos em seu processo histórico e sua formação social, é justamente a dicotomia entre sua inserção simultaneamente marinha - atlântica - e desértica saheliana. Segundo José Maria Semedo, 
Se Cabo Verde está integrado num universo essencialmente marinho que define e caracteriza seu espaço, também não é menos relevante a sua inserção no Sahel africano [, uma vasta zona de aridez que marca o limite entre o Saara e o Sudão úmido, estendendose, no continente africano, da costa atlântica ao Mar Vermelho]. O Sahel é o quadro natural que tem condicionado de forma indelével a evolução ecológica, a ocupação humana do seu território, o percurso sócio-econômico e cultural do País. É no sistema insular-saheliano que se molda a cultura cabo-verdiana. (SEMEDO, 1998, p. 32)

Assim, o dilema caboverdiano, que produziu ao longo de sua história períodos cíclicos de mortandades e emigrações em massa, aproxima-se daquele do náufrago, condenado a morrer de sede no meio de uma imensidão de água. Talvez mais do que qualquer outra nação, Cabo Verde conjuga, ao mesmo tempo, história e utopia pois, como as utopias das letras, é construída e reconstruída incessantemente sobre as faltas. Como nos disse Saramago, é o país que "fabrica o seu próprio chão, inventa a sua própria água, repete dia por dia a criação do mundo" (SARAMAGO, 1998, pp. 28-29). Nação que é, enfim, a sua própria realidade imaginada pois, como nos diz Mario Lucio em outra de suas canções, "de porta pa fora de Goré era só Atlântico" (LUCIO, 2005).

\section{Referências}

ANDERSON, Benedict. Introdução. In: Nação e consciência nacional. São Paulo: Ática, 1989.

CAMÕES, Luis de. Os Lusíadas. Introdução, notas e vocabulário do prof. António José Saraiva. $2^{\mathrm{a}}$ ed. Lisboa: Figueirinhas, 1999.

DE CAMP, L. Sprague. Lost continents. The Atlantis theme in history, science, and literature. New York: Dover, s.d.

FERREIRA, Manuel. O mito hesperitano ou a nostalgia do paraíso perdido. In: Les littératures africaines de langue portugaise. Lisboa: Fundação Calouste Gulbernkian, 1985.

FINAZZI-AGRÓ, Ettore. A invenção da ilha. Tópica literária e topologia imaginária na descoberta do Brasil. In: Remate de males, n. 13. Campinas, 1993, p. 94.

GHEERBRANT, Alain e CHEVALIER, Jean. Dicionário de símbolos. Mitos, sonhos, costumes, gestos, formas, figures, cores, números. $2^{\mathrm{a}}$ ed. Rio de Janeiro: José Olympio, 1998.

GILROY, Paul. O Atlântico Negro. Modernidade e dupla consciência. São Paulo/Rio de Janeiro: 34/Universidade Cândido Mendes, 2001.

HOLANDA, Sérgio Buarque de. Raízes do Brasil. Edição comemorativa 70 anos. Org. Ricardo Benzaquen de Araújo e Lilia Moritz Schwarcz. $1^{\text {a }}$ reimp. São Paulo: Companhia das Letras, 2006.

LUCIO, Mario. Ao vivo e aos outros. Portugal: Universidade de Aveiro, 2005. 
PEREIRA, Daniel. Estudos da História do Cabo Verde. Praia: Instituto Caboverdiano do Livro, 1986. Das relações históricas Cabo Verde/ Brasil. Brasília: Fundação Alexandre de Gusmão, 2011.

RENAN, Ernst. O que é uma nação? In: ROUANET, Maria Helena (org.). Nacionalidade em questão. Cadernos da pós-Letras, n 19. Rio de Janeiro: EdUERJ, 1997.

ROTTERDAM, Erasmo de. Elogio da Loucura. Coleção "Os Pensadores". São Paulo: Abril Cultural, 1979.

SALVADOR, Frei Vicente do. História do Brasil. São Paulo: Melhoramentos, 1965.

SARAMAGO, José. Caboverdiando. In: Jornal de Letras. Lisboa, nº 731, 14 de outubro de 1998.

SEMEDO, José Maria. Um arquipélago do Sahel. In: VVAA. Descoberta das ilhas do Cabo Verde. Praia: AHN, 1998.

SILVA, Baltasar Lopes da. O dialecto crioulo de Cabo Verde. Lisboa: Imprensa Nacional Casa da Moeda, 1984 [1 $1^{\text {a }}$ ed. 1957].

SILVA, Luiz. Kapvert - Civilização \& cultura, de Luís Romano. In: Latitudes, n 17, maio de 2003. Disponível em: http://www.revues-plurielles.org/_uploads/pdf/17_17_21.pdf. Acesso em: 01/05/2015.

SOUZA, Laura de Mello e. O diabo e a Terra de Santa Cruz. Feitiçaria e religiosidade no Brasil Colonial. $1^{\mathrm{a}}$ reimp. São Paulo: Companhia das Letras, 1987.

STRÄTER, Thomas. O Brasil, uma ilha. Revista Humboldt, ano 42, n. 80, 2000. 